\title{
GRUPO OPERATIVO COM PRIMIGESTAS: UMA ESTRATÉGIA DE PROMOÇÃO À SAÚDE
}

\author{
Operative group of primigravidae: a health promotion strategy
}

\section{Grupo operante con primigestas: una estrategia de promoción de la salud}

\author{
Maria Adelane Monteiro da Silva \\ Universidade Estadual Vale do Acaraú - UVA - Sobral - CE - Brasil
}

Flávia Martins Marques

Universidade Estadual Vale do Acaraú - UVA - Sobral - CE - Brasil

Maria da Conceição Coelho Brito

Universidade Estadual do Ceará - UECE - Fortaleza - CE - Brasil

\section{Rebeca Sales Viana}

Universidade Estadual Vale do Acaraú - UVA - Sobral - CE - Brasil

\section{Anna Larissa Moraes Mesquita}

Universidade Estadual Vale do Acaraú - UVA - Sobral - CE - Brasil

\section{Antonia Smara Rodrigues Silva}

Universidade Estadual Vale do Acaraú - UVA - Sobral - CE - Brasil

Lorena Carneiro Gomes

Universidade Estadual Vale do Acaraú - UVA - Sobral - CE - Brasil

\section{RESUMO}

Objetivo: Promover ações de educação em saúde por meio de grupo operativo com primigestas acompanhadas pela Estratégia Saúde da Família. Métodos: Pesquisa-ação com abordagem qualitativa, realizada no segundo trimestre de 2013. A coleta de informações ocorreu por meio de grupo operativo com dez primigestas, tendo como cenário a Unidade Básica de Saúde localizada na porção sul do município de Sobral, Ceará, Brasil. A análise temática foi adotada como técnica de análise de dados. Resultados: A ação do grupo operativo com as primigestas possibilitou a explicitação de variáveis relacionadas: ao medo do parto; à ansiedade diante da sensação de tornar-se mãe, identificada pelas necessidades de aprendizagem; à emissão de aspectos sinalizadores que permitiram a identificação de papéis assumidos no âmbito grupal e à compreensão desse espaço para a promoção da saúde. Evidenciou-se a importância da utilização de uma abordagem diferenciada no complemento às consultas de pré-natal, em que se associa a teoria com a prática. Conclusão: $\mathrm{O}$ grupo operativo se revelou como estratégia pedagógica e educativa a ser utilizada junto às primigestas na Estratégia Saúde da Família, no sentido da promoção à saúde. O espaço grupal possibilitou a explicitação de ansiedades/medos inerentes à primeira gestação e a oportunidade de uma construção de conhecimento coletivo.

Descritores: Gestantes; Aprendizagem; Promoção da Saúde; Atenção Primária à Saúde.

\section{ABSTRACT}

Objective: To promote health education activities in an operative group of primigravidae served by the Family Health Strategy. Methods: Qualitative action research carried out in the second quarter of 2013. Data were collected from an operative group of 10 primigravidae at a Primary Health Care center located in the south of the municipality of Sobral, Ceará, Brazil. Thematic analysis was adopted as the data analysis technique. Results: The group of primigravidae highlighted several variables: fear of delivery; anxiety surrounding motherhood, which was identified through their learning needs; aspects that allowed the identification of the roles taken within the group; and the understanding of this space for health promotion. It is evident the importance of using a differentiated approach in addition to prenatal consultations by combining theory and practice. Conclusion: The operative group proved to be an educational and pedagogical tool that should be used in primigravidae served by the Family Health Strategy to promote their health. The group allowed to highlight anxieties/fears inherent to the first pregnancy and the opportunity to build collective knowledge.

Descriptors: Pregnant Women; Learning; Health Promotion; Primary Health Care. 


\section{RESUMEN}

Objetivo: Promover acciones de educación en salud a través de un grupo operante de primigestas asistidas por la Estrategia Salud de la Familia. Métodos: Investigación-acción de abordaje cualitativo realizada en el segundo trimestre de 2013. La recogida de las informaciones se dio a través de un grupo operante con diez primigestas en el escenario de la Unidad Básica de Salud localizada en la zona sur del municipio de Sobral, Ceará, Brasil. El análisis temático ha sido adoptado como la técnica para el análisis de los datos. Resultados: El abordaje de grupo operante con las primigestas ha posibilitado la evidencia de variables relacionadas al miedo del parto; la ansiedad delante la sensación de tornarse madre identificada por las necesidades de aprendizaje; a la emisión de aspectos que permitieron la identificación de papeles asumidos en al ámbito del grupo y la comprensión de ese espacio para la promoción de la salud. Se evidenció la importancia de la utilización de un abordaje diferenciado para el complemento de las consultas prenatal en el cual se asocia la teoría con la práctica. Conclusión: El grupo operante se ha revelado como estrategia pedagógica y educativa para ser utilizada con las primigestas de la Estrategia Salud de la Familia para la promoción de la salud. El espacio del grupo ha posibilitado la evidencia de ansiedades/miedos inherentes al primer embarazo y la oportunidad de una construcción del conocimiento colectivo.

Descriptores: Mujeres Embarazadas; Aprendizaje; Promoción de la Salud; Atención Primaria de Salud.

\section{INTRODUÇÃO}

A gravidez é um processo fisiológico que envolve inúmeras alterações, com repercussões não somente nos aspectos físicos e biológicos, mas também na dimensão psíquica. Trata-se de um momento da vida da mulher em que o corpo se adapta para abrigar o feto em desenvolvimento, havendo mudanças nos níveis hormonais e diversas alterações emocionais. A ansiedade, o medo e as incertezas diante do novo afloram especialmente nas primigestas, em virtude de ser a primeira experiência gestacional, somada ao fato de que além do papel de filhas, esposas/companheiras, irão exercer o de mãe ${ }^{(1-3)}$.

O acompanhamento da gestação na Atenção Primária à Saúde (APS), a partir das consultas de pré-natal, é essencial para a garantia de uma gestação saudável e um parto seguro. Durante o pré-natal, a criação de espaços de educação em saúde é de suma importância para que as gestantes possam ouvir e falar sobre suas vivências, assim como trocar informações sobre a gestação e os aspectos que envolvem a saúde da criança. Esse processo de troca de experiências, que ocorre entre as mulheres e profissionais da saúde, é a melhor forma de promover a compreensão do processo de gestação. Portanto, a participação de primigestas em trabalhos educativos torna-se imprescindível por se tratar de espaços em que se compartilham dúvidas e experiências que normalmente não são discutidas dentro dos consultórios ${ }^{(4,5)}$.

O papel do setor saúde, além das suas responsabilidades clínicas, deve mover-se em processo gradativo no sentido da promoção da saúde, apoiando o desenvolvimento pessoal e social através da divulgação de informação e educação para a saúde. Promover a saúde é capacitar a comunidade para atuar na melhoria de sua qualidade de vida e saúde, incluindo uma maior participação no controle desse processo ${ }^{(6)}$. Nesse sentido, a abordagem educativa no contexto dos serviços de saúde é considerada eixo fundamental para a promoção da saúde ${ }^{(5)}$.

Entre as diferentes formas de realização do trabalho educativo, destacam-se as discussões grupais, no intuito de facilitar a fala e a troca de experiências entre os componentes do grupo $^{(5)}$. Na APS, o enfermeiro desempenha relevante papel na equipe e deve promover ações interdisciplinares de educação em saúde, despertando o interesse e conhecimento da comunidade ${ }^{(7)}$.

Percebe-se que o cuidado às gestantes nos serviços de saúde durante o pré-natal é quase que exclusivamente realizado em momentos individuais, no formato de consultas, e que envolve atenção relacionada aos aspectos biológicos do processo da gravidez. Os momentos em grupo com gestantes, quando ocorrem, muitas vezes são voltados para repasse de informações que não contribuem para o desenvolvimento de habilidades pessoais e não acontecem de forma sistemática, a fim de implicar na reorientação dos serviços de saúde ${ }^{(8)}$.

Buscou-se, assim, evidenciar o aprendizado interpessoal durante o processo grupal como prática educativa no sentido da promoção da saúde de primigestas. Um recurso que vem sendo empregado na APS com resultados positivos no campo da promoção, prevenção e educação em saúde ${ }^{(9)}$ é o grupo operativo. Diante desse contexto, o estudo apresenta como pressuposto que a utilização de grupo operativo pode contribuir para a promoção da saúde de primigestas.

Portanto, este trabalho tem como objetivo promover ações de educação em saúde por meio do grupo operativo com primigestas acompanhadas pela Estratégia Saúde da Família.

\section{MÉTODOS}

Trata-se de uma pesquisa qualitativa(10), na qual se optou por utilizar o método da pesquisa-ação para alcançar os objetivos propostos, pois permite que os pesquisadores desempenhem um papel ativo na própria realidade dos fatos observados ${ }^{(11)}$. 
Adotou-se como referencial teórico-metodológico o grupo operativo de Pichon-Rivière ${ }^{(12)}$, que definiu o grupo como um conjunto de pessoas ligadas no tempo e espaço, determinadas a realizar uma tarefa, interagindo em uma rede de papéis e estabelecendo vínculos entre si. O caminhar do grupo se processa em três momentos diferentes: a pré-tarefa, a tarefa e o projeto. A pré-tarefa é o momento em que preponderam mecanismos de dissociação, objetivando defender os sentimentos de culpa e ambivalência, a situação depressiva básica, as dificuldades de tolerância, a frustração e a postergação. A tarefa é o período em que se rompe a estereotipia e se organiza a pré-tarefa, prosseguindo na preparação de seu objetivo. Nesse momento, conseguese maior operatividade e criatividade, podendo-se sistematizar objetivos e alcançar tarefas propostas e/ou novas. No momento do projeto, uma vez alcançado um nível de operatividade, o grupo pode se planejar ${ }^{(12)}$.

Durante o processo grupal ocorre ambivalências, regressão, dispersão diante do constante processo de sustentar e prever, necessitando estar sempre se reorganizando, processo chamado de espiral dialética, o qual compreende o todo do processo grupal, como um movimento constante entre processos internos ao grupo, que pode ser notado tomando-se como referência os indicadores do processo grupal, quais sejam: afiliação/pertença, cooperação, comunicação, aprendizagem, pertinência e tele ${ }^{(12)}$.

A afiliação e a pertença relacionam-se com o grau de identificação dos membros do grupo entre si e com a tarefa. A cooperação implica ajuda mútua e se dá mediante o desempenho de diferentes papéis e funções. A comunicação é um processo que considera as redes de comunicação no grupo. A aprendizagem diz respeito ao desenvolvimento da capacidade de idealizar opções, percebendo-se o grau de plasticidade grupal diante dos obstáculos e da criatividade para sobrepujar as contradições e mesmo integrá-las. A pertinência relaciona-se à produtividade do grupo, à sua capacidade de centrar-se em seus objetivos de forma coerente com seus outros processos. E a tele surge como uma rede de transferências, que se traduz pelas interações positivas ou negativas dos membros do grupo entre $\mathrm{si}^{(12)}$.

A coleta de dados ocorreu no segundo trimestre de 2013, em uma Unidade Básica de Saúde que atende a comunidade de um bairro localizado na porção sul do município de Sobral, Ceará, Brasil. O município está localizada no sertão, na porção Noroeste do estado do Ceará, distante $235 \mathrm{~km}$ da capital Fortaleza e ocupa uma área de 2.129 quilômetros quadrados, com população estimada pelo Instituto Brasileiro de Geografia e Estatística (IBGE) em 155.276 habitantes e está a uma altitude de 70 metros. No setor saúde, constitui referência para toda a região Norte do estado, sendo considerado polo assistencial da região ${ }^{(13)}$.

O interesse pelo presente estudo surgiu a partir de vivências nas Unidades Básicas de Saúde do município de Sobral, Ceará, Brasil, nas quais se evidenciou o tempo insuficiente das consultas de pré-natal para suprir as necessidades de aprendizagem em saúde das primigestas. Esta iniciativa também foi norteada pela participação das autoras no Projeto de Extensão Saúde da Mulher e pelo envolvimento nesta linha de pesquisa desde o módulo Gravidez, Nascimento e Desenvolvimento Infantil, que compõe a grade curricular do curso de Enfermagem de uma universidade da região.

Participaram do estudo primigestas residentes no bairro e acompanhadas pela Estratégia Saúde da Família do referido local. Fez-se necessário o levantamento do número de primigestas assistidas, realizado com base nos prontuários disponibilizados, em que constatou-se um total de 42 gestantes. As agentes comunitárias de saúde (ACS) realizaram busca ativa de gestantes no território. Quatorze gestantes estiveram presentes nas ações de educação em saúde, porém considerou-se como participantes da pesquisa somente aquelas que tiveram presença assídua em relação aos encontros (mínimo três encontros). Dessa forma, fizeram parte do estudo dez gestantes.

A pesquisa foi desenvolvida em três etapas, correspondentes às da pesquisa-ação ${ }^{(11)}$. A primeira foi direcionada à fase exploratória de identificação da problemática da pesquisa e estabelecimento do primeiro contato com as primigestas, cujo contato deu-se de forma individual, obtendo-se informações pessoais e obstétricas (faixa etária, idade gestacional). Em seguida, a partir de uma roda de conversa, apurou-se a visão das participantes sobre a gravidez e suas necessidades de aprendizagem. Esse momento contribuiu também para uma aproximação entre pesquisadoras e gestantes. A segunda etapa correspondeu à elaboração de um plano de ação para a intervenção na realidade, sendo definidos os modos pelos quais a tarefa seria alcançada e a periodicidade e duração dos encontros. Ocorreram cinco encontros semanais, com duração de aproximadamente uma hora, os quais foram permeados pelas ações de educação em saúde no espaço grupal. Os temas trabalhados trataram sobre o desenvolvimento fetal; mitos e verdades relacionados à gestação; parto; amamentação e cuidados com o recém-nascido. A terceira etapa foi destinada à avaliação do processo grupal, pautada nos relatos das primigestas. Essa etapa enfocou a aprendizagem durante o grupo operativo, bem como a satisfação das participantes em relação à experiência. Para isso, indagouse: O que você aprendeu e qual a sua satisfação em relação aos assuntos discutidos?

Para a coleta de informações, utilizou-se a observação participante e o diário de campo. Por conseguinte, adotou-se a Análise Temática ${ }^{(14)}$ como técnica de análise da pesquisa, a qual se desdobra operacionalmente em três etapas: pré-análise, exploração do material e tratamento dos dados obtidos. Assim, a análise dessas implicações possibilitou a constituição de três categorias temáticas: A explicitação do implícito no trabalho grupal com primigestas; Processo grupal: papéis e vetores envolvidos em um contínuo espiral; O grupo como espaço de aprendizagem e transformação para primigestas.

O estudo seguiu em conformidade com a Resolução 466/12 ${ }^{(15)}$, tendo sido aprovado pelo Comitê de Ética em Pesquisa (CEP) sob o Parecer $n^{\circ}$ 420.428. O anonimato das participantes foi assegurado, sendo identificadas na pesquisa como Primigestas (P), seguidas de um numeral ordinal, em ordem crescente (P1, P2, P3...). A participação das gestantes se deu mediante o 
reconhecimento dos objetivos da pesquisa e a partir da anuência por meio da assinatura do Termo de Consentimento Livre e Esclarecido (TCLE).

\section{RESULTADOS E DISCUSSÃO}

Nesse tópico, serão apresentados os dados de identificação das gestantes e as categorias temáticas emergidas no estudo a partir da realização das ações educativas no grupo operativo com primigesta.

\section{Dados de identificação das gestantes}

A faixa etária das participantes variou entre 16 e 30 anos e as mesmas estavam com idade gestacional compreendida entre 16 a 28 semanas de gestação.

\section{A explicitação do implícito no trabalho grupal com primigestas}

Diante do contato inicial, as participantes demonstraram receio em expor os seus pensamentos, dúvidas, inquietações ou histórias de vida, apenas concordando, principalmente por meio da linguagem não verbal. No entanto, as primigestas foram estimuladas a expressarem seus sentimentos, tornando explícitas emoções e sensações, as quais muitas vezes, passam despercebidas até mesmo por elas e frequentemente não são verbalizadas durante o acompanhamento pré-natal.

No processo gestatório, a mulher vive uma transição de sentimentos que podem inicialmente ser negativos, como preocupações e medo. Dependendo do contexto social em que ela está inserida, podem se tornar positivos, como a satisfação com a gravidez. Essa transição é permeada por sentimentos de ambivalência ${ }^{(4)}$. Assim, é importante considerar o contexto em que as gestações ocorrem, pois pode haver insatisfação materna, como por ocasião da separação do companheiro, e não somente com a gravidez não planejada ${ }^{(16)}$.

Dessa forma, os sentimentos não são semelhantes em todas as gestantes e podem ser expressos de formas diferentes. A gravidez se configura em um período de reestruturação emocional e social na vida de cada mulher, e, dependendo da experiência vivida, sentimentos positivos e/ou negativos podem ser manifestados ${ }^{(8)}$ :

\section{"Eu queria muito saber como meu bebê está crescendo dentro de mim" (P10). \\ "Eu acho que minha insegurança é na hora de ter realmente o bebê [...] porque eu já vi e fiquei com medo" (P3). \\ "Eu tenho muito medo de banhar o bebê [...] tenho medo do meu filho chorar e eu não saber o que é, o que ele está sentindo" (P4). \\ "Em novembro eu pintei o cabelo sem saber que estava grávida, porque eu estava esperando a menstruação, será que fiz mal?” (P7).}

No trabalho grupal com primigestas, o implícito, caracterizado por medos, situações insatisfatórias ou inseguranças, tornou-se nítido a partir do momento em que passaram a falar de suas ansiedades, abrindo-se, dessa forma, para o novo e o desconhecido espaço grupal. Concorda-se que, a partir da formação do grupo de gestantes, é possível oferecer acolhimento, interação entre as participantes e favorecer a expressão significativa de suas emoções. Configura-se como oportunidade para revelar sentimentos e limitações ocultas, tanto em nível individual como coletivo ${ }^{(4)}$.

O medo em relação ao parto constituiu um sentimento explícito nas falas das participantes. Entende-se que, apesar de hoje o acesso à informação tenha se difundido, ocorrendo através de diversas fontes, as informações obtidas sobre o parto normal não alcançaram um caráter educativo que favorecesse a promoção de segurança psicoemocional da primigesta em relação à futura vivência parturitiva. Assim, as gestantes constroem percepções ambíguas da dor conforme seu meio sociocultural e de assistência pré-natal, que repercutem em sentimentos também dúbios, de inquietação, sofrimento e, ao mesmo tempo, otimismo $^{(17)}$.

A representação social que as primigestas têm quanto ao parto revelam sentimentos de medo, dor e sofrimento relacionados ao despreparo em relação ao tipo de parto e à falta de subsídios para tomada de decisão quando lhe for possível ${ }^{(18)}$. O sentimento de medo também se destacou em estudo realizado na Suíça com primigestas. No entanto, houve a expressão da fé pelas mulheres de que seus corpos lidariam de forma positiva com a experiência do parto ${ }^{(19)}$.

Cabe destacar que conhecer as necessidades de aprendizagem das gestantes durante o pré-natal é considerar a importância da cliente na determinação de seu autocuidado ${ }^{(20)}$. As participantes do presente estudo mencionaram aspectos relacionados ao desenvolvimento fetal; aos mitos e verdades sobre a gestação; ao processo de trabalho de parto e ao parto propriamente dito; à amamentação e aos cuidados com o recém-nascido. A partir desse momento, tornou-se possível definir o objetivo comum do grupo, que se configurou na aprendizagem. Ressalta-se que o estabelecimento do objetivo se deu por meio do compartilhamento de medos e angústias e com a participação de todas as integrantes.

Ressalta-se que uma condição necessária para a inclusão em grupos é a aceitação de si próprio, e o primeiro movimento para alcançá-la é expor-se diante de si mesmo, sendo necessário fazer a opção de expor-se, ou de resguardar-se, diante do outro. 
Somado a isso, para que ocorra o compartilhamento de experiências, o ambiente deve ser acolhedor ${ }^{(21)}$. Dessa forma, destacase a importância de promover um ambiente afável e de confiança, atentando-se para aspectos que melhorem a ambiência, como ilustrações, objetos, fundo musical, disposição dos integrantes em círculo, de modo a promover o acolhimento e a integração entre as participantes do grupo, o que contribui para a exposição de aspectos até então internalizados, permitindo uma construção coletiva.

Assim, a atuação com grupos de gestantes, especialmente primigestas, deve buscar a explicitação do implícito, em que predominam as resistências à mudança, representadas tanto pelo medo como pela imersão numa situação nova, que passa a ser vivenciada como uma ameaça. No caso das primigestas participantes do grupo em estudo, considera-se que o medo do parto e a insegurança em relação aos cuidados com o futuro filho foram explicitados, configurando-se como norteadores para o plano de ação e da tarefa. A explicitação do implícito é um fator que contribui para o grupo caminhar em direção à tarefa ${ }^{(22)}$.

\section{Processo grupal: papéis e vetores envolvidos em um contínuo espiral}

Nesta categoria, as atividades que compuseram o plano de ação construído juntamente com as gestantes estão descritas para potencializar o alcance dos objetivos traçados para o grupo. Também são destacados os papéis desempenhados pelas participantes, bem como a interação entre elas, essenciais para a execução da tarefa.

Para atuação junto ao medo verbalizado pelas gestantes, as facilitadoras buscaram promover momentos com técnicas de relaxamento, com exercícios de respiração e automassagem. Também procurou-se desmistificar padrões culturais estabelecidos acerca da dor do parto a partir de discussões permeadas pela reflexão/problematização. Esse movimento educativo e dialógico de discussão permeou o processo grupal.

O processo grupal se refere a tudo, ou quase tudo, que acontece durante o funcionamento de um grupo, incluindo o conteúdo do que é dito, a interação entre os membros e os papéis emergentes ${ }^{(23)}$. Nesse sentido, estudos que experimentaram o efeito de intervenções educativas no preparo para o parto em mulheres primigestas evidenciaram que, ao fornecer educação em saúde no pré-natal, elas tiveram uma experiência positiva em relação ao parto, consequência do enfrentamento do medo e do bem-estar físico gerado. Mantiveram comportamento e atitude de controle, sendo encorajadas para a escolha da posição do parto normal. Assim, foi sugerido um trabalho educativo contínuo com primigestas, com vistas a proporcionar percepções positivas e diminuir o medo em relação à dor do parto ${ }^{(24,25)}$.

Outras experiências estão relacionadas ao efeito de métodos de relaxamento na redução de ansiedade e estresse de primigestas. Após duas sessões de relaxamento e quatro semanas de exercícios executados no domicílio, esses métodos têm se mostrado eficazes, sem efeitos colaterais e de fácil aplicação, sendo recomendados como abordagem para reduzir a ansiedade e estresse em mulheres durante a primeira gravidez ${ }^{(26)}$.

O grupo operativo proporciona a seleção de técnicas adequadas para a ação grupal, atuando numa perspectiva transformadora, na qual os participantes de um grupo sejam vistos como sujeitos capazes de uma construção conjunta ${ }^{(21)}$. Devese, portanto, favorecer que os integrantes mudem e se adaptem à nova realidade, um processo de aprendizagem contínua, em espiral, mediante movimentos dialéticos de indagação ${ }^{(12)}$.

Nesse sentido, ao longo do grupo operativo, os participantes passam a assumir diferentes papéis e posições frente à tarefa grupal, que devem ser identificados, visto que alguns podem atuar como obstáculo ao alcance da tarefa. Durante o trabalho com as primigestas investigadas na presente pesquisa, não foi evidenciado nenhum papel que comprometesse o caminhar em direção ao alcance da aprendizagem, tarefa que foi elencada pelas participantes, não havendo a cristalização de papéis no grupo, e sim a assunção e a adjudicação, que representa o movimento em espiral ${ }^{(12)}$.

Foi evidente a assunção do papel de porta-voz pela Primigesta 3, que verbalizou ao iniciar o momento de discussão sobre o medo da dor do parto:

\section{“[...] todo mundo aqui tem medo de tudo, porque é a primeira gravidez” (P3).}

Percebe-se que, naquele momento, ela desempenhava um papel assumido no grupo de falar por aquelas que ainda não se sentiam totalmente à vontade. Todas sorriram, confirmando que sim. Aos poucos, as participantes reafirmaram o que Primigesta 3 havia dito, o que otimizou a discussão sobre os mitos em relação ao parto normal.

Essa postura de trabalhar a verticalidade e a horizontalidade, colaborando com a tarefa, permite o aparecimento da figura do líder de mudança, resultando na troca de informações.

A Primigesta 6 apropriou-se do papel de líder diante de uma atividade proposta, quando sugeriu:

$$
\text { “[...] Vamos confeccionar um cartaz que todo mundo participe... dê sua ideia [...]” (P6). }
$$

A construção de um cartaz configurou-se como proposta de levantamento do conhecimento prévio, bem como das crenças em relação ao parto normal. A criação conjunta de um cartaz em que cada gestante pudesse participar favoreceu a interação entre as mesmas, valorizando o saber individual na construção do conhecimento coletivo. Na dinâmica grupal, a criação de laços, troca de vivências comuns e o sentimento de pertencimento fortalecem as capacidades individuais e coletivas, encorajam 
os indivíduos a buscarem novas estratégias para compreender seus problemas, a fim de minimizá-los ou resolvê-los, além de fortalecê-los para enfrentar os desafios ${ }^{(27)}$.

O compartilhamento de vivências, enquanto forma de significar os assuntos debatidos, esteve presente durante os momentos de promoção à saúde das primigestas, favorecendo a exposição de experiências complementares que ocorreram no próprio seio familiar, ou no círculo de amizade, como forma de reconstruir atitudes futuras. Uma das discussões envolveu a questão do aleitamento materno e a importância da persistência da figura materna para a superação de situações que surgem no processo de cuidar do bebê:

"Eu vi uma mãe que eu achei bonito o que ela fez. Ela dava leite ao bebê e ele não queria, mamava poucas vezes, mas ela foi dedicada e conseguiu dar só mama até os seis meses” (P1).

"A gente vai passar por isso e a gente vai ver que é dificil. Eu já vi várias mulheres que não conseguem amamentar e outras que dá certo. Não pense que vai ser uma maravilha não, a mãe tem que ter muita dedicação! A amamentação é muito importante para mãe e para o bebê" (P7).

“Acho que não deve ser fácil não, mas, se a gente tiver força de vontade, a gente consegue” (P2).

A maternidade faz parte do ciclo de vida da mulher e exige dedicação, reajustamento de vida, resiliência, para que essa experiência possa ser vivida de maneira mais tranquila possível. Para tanto, torna-se necessário que os profissionais de saúde que assistem essas mães estejam sensíveis às necessidades dessas mulheres, prestando uma assistência qualificada ${ }^{(8)}$.

A constatação sistemática e reiterada de certos fenômenos grupais, que se apresentam em cada sessão, permite classificar condutas grupais, ou indicadores do processo grupal, que recebem a denominação de vetores, como já mencionados: a afiliação e pertença, tele (grau de empatia positiva ou negativa que se dá entre os membros do grupo), pertinência, aprendizagem, cooperação e comunicação ${ }^{(12)}$.

Nas falas das Primigestas 1 e 2 observa-se o clima de cooperação estabelecido no trabalho grupal no que diz respeito ao alcance do objetivo definido e diante da partilha de uma experiência. Percebe-se que, a partir do compartilhamento, houve o encorajamento e o apoio entre as participantes. A cooperação consiste justamente na contribuição interpessoal na direção da tarefa. É através desse vetor que se torna manifesto o caráter interdisciplinar do grupo operativo ${ }^{(21,27)}$.

No que se relaciona à pertinência, está relacionada ao grau de centramento do grupo na tarefa, evidenciado pela assiduidade das primigestas nas sessões grupais para o alcance da aprendizagem. A satisfação pelo processo de construção do conhecimento, com base nos aspectos emergentes durante a transição da fase da pré-tarefa para a tarefa ${ }^{(12)}$, é evidenciada em vários momentos no caminhar do grupo:

\section{“É bom vir, eu adoro estar aqui, eu fico ansiosa pra vir!” (P 8). \\ “Adoro os momentos que nós passamos juntas [...]” (P5). \\ "A gente aqui teve o companheirismo e a cumplicidade” (P 6).}

Quando a pré-tarefa foi retomada, remeteu-se a outro vetor, afiliação e pertença. A afiliação é própria da história de todo grupo, convertendo-se mais tarde em pertença, ou seja, na interação grupal. Na afiliação, o sujeito guarda uma determinada distância, sem incluir-se totalmente no grupo. Já a pertença é uma maior integração ao grupo, o que permite aos membros elaborar uma estratégia, uma tática, uma técnica e uma logística ${ }^{(27)}$.

Nesse contexto, é possível identificar, a partir das falas das Primigestas 5 e 8, uma das fases características do grupo operativo, o projeto, que surge justamente quando se consegue uma pertença dos membros do grupo, ou seja, uma sensação de "estar integrado"(12). As pesquisadoras perceberam uma total interação das primigestas no momento destinado à abordagem sobre o tema amamentação, que resultou na construção conjunta de um conceito sobre o ato de amamentar: "Amamentar é um ato de dedicação, emoção e amor em nossas vidas".

Entende-se que a constituição da grupalidade e coesão se dá por meio do encontro sucessivo entre os participantes e a equipe coordenadora do grupo, sendo construída pelos diálogos, ditos e não ditos que se expressam no movimento grupal. Do mesmo modo, o sentimento de pertença indica que os participantes desejam permanecer nos grupos pelo reconhecimento de seus saberes e de suas necessidades afetivas, sociais e de saúde ${ }^{(28)}$.

O companheirismo e cumplicidade referidos pela Primigesta 6 denotam a sensação agradável e prazerosa de poder compartilhar informações e receber apoio das demais participantes, permitindo um ambiente proveitoso, de interesse para as gestantes. Houve de fato uma tele positiva durante todo o percurso grupal estabelecido, considerando que esse vetor se refere ao clima grupal, voltado para a capacidade que cada indivíduo tem para trabalhar com outras pessoas ${ }^{(21)}$.

Observou-se no grupo de gestantes o surgimento a cada encontro de sentimentos referentes às relações estabelecidas entre as participantes, como empatia, carinho, afeto, tornando-as cada vez mais próximas. A convivência entre as mulheres se fortalecequando se constroem relações de companheirismo, cuidado e amizade que vão além do ambiente do grupo ${ }^{(8)}$.

Dessa forma, percebe-se que vários elementos estão envolvidos no processo de um grupo constituído por primigestas, os quais devem ser identificados a fim de manter o constante movimento em espiral, permitindo a troca de experiências, favorecer 
um ambiente saudável para a aprendizagem em saúde, na busca de transformações pessoais e construção do conhecimento coletivo para além do espaço grupal, de forma que as futuras mamães carreguem esse aprendizado ao longo de suas vidas.

\section{O grupo como espaço de aprendizagem e transformação para primigestas}

Os resultados obtidos a partir da experiência grupal são apresentados nesta categoria, ressaltando a aprendizagem alcançada enquanto objetivo traçado pelo grupo e a tarefa a ser realizada pelas gestantes.

A aprendizagem, considerada um dos vetores envolvidos no processo grupal, merece destaque em virtude de tratar de tarefa designada pelas primigestas. Cabe ressaltar que a aprendizagem é um dos indicadores fundamentais no processo grupal ${ }^{(29)}$. É obtida pela somatória de informações compartilhadas entre os que integram o grupo, reforçando a dialética como ponto de transformação do quantitativo em qualidade ${ }^{(27)}$.

"Foi muito importante para gente estar participando do grupo, como primeira gestação a gente aprendeu muita coisa" (P10).

"Foi uma experiência boa participar do grupo, eu não sabia de nada, eu não sabia como banhar o bebê, mas agora eu já sei, também não sabia como botar o bebê para mamar [...]” (P7).

"Eu achei muito bom as orientações de vocês, gostei muito dos encontros, eles passaram mais segurança para a gente" (P3).

Salienta-se a fala da Primigesta 10 no que concerne à atenção que deve ser dispensada às mulheres que experimentam a gravidez pela primeira vez. Identificar se a gravidez é desejada, ou não, bem como considerar o contexto social ${ }^{(16)} \mathrm{em}$ que a mulher está inserida, é tão importante quanto atender aos seus anseios relacionados às necessidades de aprendizagem, deixandoas mais seguras.

Estudos que descrevem a experiência de grupos de gestantes referem que elas expõem suas necessidades de aprendizagem no desejo de que os momentos de diálogos envolvam a discussão sobre seu problema. Percebe-se a ânsia por uma aprendizagem significativa, de acordo com cada realidade, que possa ir ao encontro do que elas estejam vivenciando. Acredita-se que só a partir de uma abordagem com essa acepção é possível auxiliá-las durante a gravidez e nos cuidados com seu filho ${ }^{(8,28)}$.

Os paradigmas atuais de educação em saúde colocam o sujeito no centro de seu processo de aprendizagem. A oportunidade de trocar saberes e vivências, de expressar sentimentos e medos, de conhecer experiências e refletir sobre situações semelhantes às suas, possibilita a construção coletiva do conhecimento, o fortalecimento de seus recursos pessoais e a reelaboração de suas compreensões, resultando em sujeitos ativos e protagonistas na produção de sua saúde ${ }^{(30,31)}$.

O processo pedagógico e educativo que permeou o processo grupal se deu mediante abordagem dialógica, crítica e reflexiva, de forma que as primigestas pudessem alcançar o aprendizado. Para tanto, empregaram-se metodologias ativas durante os encontros, utilizando-se como recursos: o uso de imagens, músicas, tarjetas, placas com as descrições "sim" e "não", dramatização, confecção de cartazes, demonstração com manequins, entre outros:

\footnotetext{
"A gente gosta desse tipo de apresentação, porque a gente aprende mesmo, a gente vê que a teoria junto com a prática é melhor" (P6).

"Eu achava que esses momentos iam ser chatos, porque tem vezes que, quando chamam a gente para o posto, só falam besteira, não falam nem no assunto” (P1).

"Foi muito interessante, emocionante, alegre, divertido e proveitoso [...]. Foi muito bom e muito gratificante para mim, não foi aquela coisa monótona. A gente ria, a gente brincava” (P9).
}

As falas das primigestas retratam a importância da utilização de uma abordagem diferenciada no complemento às consultas de pré-natal, em que se associa a teoria com a prática, enfatizando sua importância para a aprendizagem. A utilização de uma diversidade de recursos nas abordagens educativas está em conformidade com o que o Ministério da Saúde preconiza em termo da realização de trabalhos educativos. Há destaque para as discussões grupais, as dramatizações e dinâmicas que facilitem a troca de informações entre os componentes do grupo, em que o profissional de saúde atua como facilitador e evita o estilo "palestra". Esse modelo ainda é utilizado e caracteriza-se por seguir um roteiro preestabelecido, o que impede a discussão de assuntos mais relevantes para as pessoas presentes no momento, o que acaba sendo, portanto, pouco produtivo ${ }^{(32)}$.

Entende-se que a prática de grupos faz parte do cotidiano dos profissionais de saúde que atuam na ESF. Entretanto, percebe-se que a condução dos momentos grupais é realizada muitas vezes sem fundamentação teórica e/ou metodológica, impossibilitando a concretização de práticas assertivas, que levem à problematização e reflexão sobre a realidade dos envolvidos. Os grupos geralmente acontecem sem planejamento, permeados pela transmissão de conhecimentos, sem envolvimento ativo dos participantes, desvalorizando-se as práticas que conduzam à promoção da saúde ${ }^{(8)}$. Concorda-se que os grupos focados na doença nem sempre são atrativos e podem não ser eficientes por essa razão ${ }^{(28)}$. 
Assim, acredita-se que os grupos com gestantes primigestas precisam atingir as necessidades aqui evidenciadas e o tipo de abordagem e as relações estabelecidas no espaço grupal podem ser fatores que contribuem para a participação efetiva das gestantes, de forma que alcancem a mudança.

Um estudo sobre os padrões de interação entre profissionais da saúde e usuários nas práticas educativas grupais na Atenção Básica à Saúde identificou que ainda ocorrem abordagens pautadas no fornecimento de informações a partir da transmissão de conhecimento. Entretanto, também evidenciaram-se práticas em que os profissionais confiam que os usuários possam aprender uns com os outros e em que há produção de conhecimento por meio da problematização, em que facilitador e usuários ensinam e aprendem juntos ${ }^{(33)}$.

As práticas educativas com as primigestas se deram por meio da interação entre o conhecimento técnico e o popular através do diálogo, respeitando a realidade dos envolvidos. As participantes utilizavam a denominação "mês" para se referirem à idade gestacional, assim, discutiu-se sobre o tema desenvolvimento fetal mês a mês, e não por semanas de gestação, como calculado pelos profissionais da saúde. Nesse processo, destaca-se o diálogo aberto para uma nova cultura participativa, que acolhe e legitima a contribuição do saber popular ao lado do saber técnico científico ${ }^{(5)}$.

Esse compartilhamento do saber técnico e popular proporciona o aprendizado tanto de quem "ensina" como de quem "está disposto a aprender". Esse ponto de vista foi exposto durante o grupo operativo com as primigestas, quando também se evidenciou que o objetivo do grupo, a aprendizagem, de fato foi alcançado:

"Da mesma forma que a gente aprendeu, vocês aprenderam com a gente também" (P5).

"Tudo o que eu não sabia eu aprendi aqui! Hoje quero aprender mais" (P4).

Nessa concepção, o aprendizado no grupo ocorre de forma interacional entre seus integrantes e também entre esses e seus coordenadores. Isso remete a um clima de plena interação, caracterizando a unidade do ensinar-aprender, pois, na medida em que indagam, descobrem-se ou redescobrem-se, aprendem e ensinam ${ }^{(27,31)}$.

Outra questão importante apontada pelas gestantes investigadas diz respeito ao tempo insuficiente destinado às consultas de pré-natal. Isso pode estar relacionado à alta demanda de pessoas que buscam atendimento, à organização dos serviços e/ou ao número reduzido de profissionais que compõem a equipe de saúde ${ }^{(34)}$. Essas barreiras contribuem para dificultar o suprimento das necessidades de aprendizagem das primigestas:

'Tem muita coisa no pré-natal que não dá tempo do enfermeiro falar e é importante estarem desenvolvendo essa ação para gente estar aprendendo. A gente tem o direito de tirar nossas dúvidas" (P3).

Estudos que abordam a importância do pré-natal, ou especificamente as ações educativas no pré-natal, mostram que mesmo tendo realizado as consultas, as gestantes demonstram insatisfação no que se refere às orientações prestadas ${ }^{(20)}$. Leva-se em consideração que os sentimentos das mães em relação à gestação e ao seu bebê são influenciados não só pelo tipo de assistência pré-natal recebida, mas pela sua qualidade ${ }^{(35)}$.

O desenvolvimento de ações de educação em saúde deve se configurar em uma perspectiva dialógica, emancipadora, participativa, criativa e que contribua para a autonomia do usuário e dos profissionais ${ }^{(5)}$. Chama a atenção a fala de Primigesta 3 ao se referir que tem o direito de tirar suas dúvidas. Compreende-se que o termo 'tirar dúvidas' aqui expressa a necessidade de aprendizagem das gestantes participantes e configura-se como parte importante de sua saúde e qualidade de vida. Esse fato precisa ser levado em conta para a qualidade da atenção às primigestas, sendo considerado um direito.

Os profissionais de saúde que atuam na Estratégia Saúde da Família, portanto, podem desenvolver práticas de cuidado às gestantes utilizando tecnologias leves em saúde, que fortaleçam a interação com os profissionais, possibilitem vínculospor meio de escuta qualificada, da participação ativa e da responsabilização para o cuidado. Considera-se o grupo como uma das tecnologias leves que pode ser utilizada para aproximação das gestantes e dos profissionais de saúde, em que o espaço grupal é valorizado para o alcance da integralidade do cuidado e como dispositivo potencializador para o empoderamento do ser humano ${ }^{(8,28)}$.

O presente estudo aborda uma prática que pode ser replicada na APS, a partir do aprendizado e conhecimento construído por meio do relacionamento interpessoal, enquanto estratégia que favorece o empoderamento das gestantes. Logo, espera-se contribuir para a construção de uma assistência mais humanizada, com uma abordagem diferenciada da visão tradicional do modelo biomédico.

As ações de promoção à saúde direcionadas às mulheres grávidas podem ser desenvolvidas individualmente e também coletivamente nos grupos de gestantes. Acredita-se que o grupo se constitua em um espaço criativo, interativo e oportuno para atuação com foco em vários aspectos da promoção da saúde, inclusive de primigestas.

Durante a vivência da primeira gestação, os encontros grupais tornam-se importantes, pois é nessa fase da vida da mulher que ela necessita de informações para que haja uma compreensão acerca do processo gravídico, contribuindo para o desenvolvimento saudável do feto. Por isso, o enfermeiro, ao desempenhar seu papel centrado no cuidado, deve buscar conhecimento e investir no espaço grupal como estratégia para a gestante adquirir autonomia e, assim, aumentar a sua capacidade de resolver os problemas. Essa configuração proposta permite a abordagem de assuntos de interesse para as primigestas, a depender do momento em que 
se encontram e como se sentem, o que contribui para a diferenciação na realização do trabalho educativo em saúde, não cabendo ao facilitador decidir e impor as temáticas a serem trabalhadas.

Todavia, entende-se que as ações voltadas às gestantes na APS devem ser desenvolvidas no sentido de buscar a promoção da saúde, favorecendo o autocuidado e visando a melhoria da qualidade de vida. Assim, torna-se mister o reconhecimento por parte dos profissionais da saúde, em especial os enfermeiros, acerca da utilização da abordagem grupal voltada às gestantes, no que diz respeito à escuta e discussão de temas de interesse às participantes, colaborando para promoção da saúde durante essa fase da vida da mulher. O enfermeiro, ao desempenhar seu papel centrado no cuidado, deve realizar práticas que promovam a saúde das grávidas, permitindo a construção do saber coletivo, a aquisição de hábitos saudáveis e de posturas resolutivas.

\section{CONSIDERAÇÕES FINAIS}

O grupo operativo se revelou uma estratégia pedagógica e educativa a ser utilizada junto às primigestas na Estratégia Saúde da Família no sentido da promoção à saúde. O espaço grupal possibilitou a explicitação de ansiedades/medos inerentes à primeira gestação e a oportunidade de uma construção de conhecimento coletivo. O medo do parto e a necessidade de aprendizagens relacionada ao cuidado com o futuro filho emergiram durante os encontros, fundamentando a definição de um objetivo comum para as primigestas. $\mathrm{O}$ envolvimento das participantes num processo dialético, caracterizado pela representação em espiral e marcado pelo compartilhamento de experiências, escuta, assunção e adjudicação de papéis, permitiu o alcance desse objetivo.

Percebeu-se que o grupo contribuiu não só no que diz respeito à aprendizagem das primigestas, que buscaram formas próprias para o enfrentamento de suas necessidades, mas também propiciou um espaço de cumplicidade e companheirismo, um ambiente agradável, interessante e prazeroso, que se constitui uma fonte motivacional para a continuidade e o alcance da tarefa.

O grupo operativo é uma relevante estratégia educacional que pode ser utilizada em variados contextos, inclusive na atenção às gestantes primigestas na APS, por estar centrado na aprendizagem e na transformação. Mostrou ser eficaz ao utilizar recursos não adotados com frequência nas abordagens educativas de promoção da saúde no âmbito da Atenção Primária.

Espera-se que os profissionais da saúde reconheçam a importância de se adotar um referencial metodológico para a condução de grupos e ampliem a visão para as variáveis envolvidas durante o processo grupal, permitindo uma troca de saberes criativa e eficaz, que ofereça acolhimento e assegure uma transformação positiva na realidade das pessoas envolvidas.

\section{CONFLITOS DE INTERESSE}

Autores declaram que não há conflito de interesses nesse artigo.

\section{REFERÊNCIAS}

1. Mamede FV, Stefanello J, Mamede MV. Condução da assistência pré-natal. In: Silva IA, Souza KV, Souza IEO, organizador. Programa de atualização em enfermagem PROENF: saúde materna e neonatal. Porto Alegre: Artmed/Panamericana; 2009. p. 79-114.

2. Vieira BD, Parizotto APAV. Alterações psicológicas decorrentes do período gravídico. Unoesc \& Ciência ACBS [Internet]. 2013 [acesso em 2017 Jun 24];4(1):79-90. Disponível em:http://editora.unoesc.edu.br/index.php/acbs/article/view/2559

3. Simas FB, Souza LV, Scorsolini-Comin F. Significados da gravidez e da maternidade: discursos de primíparas e multíparas. Psicol Teor Prat [Internet]. 2013 [acesso em 2017 Jun 24];15(1):93-102. Disponível em: http://pepsic.bvsalud. org/scielo.php?script=sci_arttext\&pid=S1516-36872013000100002

4. Leite MG, Rodrigues DP, Sousa AAS, Melo LPT, Fialho AVM. Sentimentos advindos da maternidade: revelações de um grupo de gestantes. Psicol Estud [Internet]. 2014 [acesso em 2015 Ago 16]19(1):115-24. Disponível em: http://www.scielo. br/pdf/pe/v19n1/12.pdf

5. Ministério da Saúde (BR), Secretaria de Gestão Estratégica e Participativa. II Caderno de educação popular em saúde. Brasília: Ministério da Saúde; 2014.

6. Ministério da Saúde (BR), Secretaria de Políticas de Saúde. Projeto Promoção da Saúde. As Cartas da Promoção da Saúde. Brasília: Ministério da Saúde; 2002.

7. Gurgel MGI, Alves MDS, Moura ERF, Pinheiro PNC, Rêgo RMV, Passos MLL. Promoção da saúde no contexto da estratégia saúde da família: concepções e práticas da enfermeira. Esc Anna Nery Rev Enferm [Internet]. 2011 [acesso em 2015 Set 05];15(3):610-15. Disponível em: http://www.scielo.br/pdf/ean/v15n3/a24v15n3.pdf

8. Cavalcante VOM. Tecnologia grupal para promoção da saúde de gestantes na estratégia saúde da família [dissertação]. Sobral: Universidade Estadual Vale do Acaraú; 2016. 
9. Menezes KKP, Avelino PR. Grupos Operativos na Atenção Primária à Saúde como prática de discussão e educação: uma revisão. Cad Saúde Colet (Rio de J.). 2016;24(1):124-30.

10. Vieira MMF, Zouain DM. Pesquisa qualitativa em administração: teoria e prática. Rio de Janeiro: FGV; 2005.

11. Thiollent M. Metodologia da pesquisa-ação. 13a ed. São Paulo: Cortez; 2004.

12. Pichon-Rivière E. O processo grupal. $7^{\mathrm{a}}$ ed. São Paulo: Martins Fontes; 2005.

13. Ceará. Prefeitura Municipal de Sobral. A Cidade de Sobral [acesso em 2017 Jun 20]. Disponível em:http://www.sobral. ce.gov.br/cidade/sobral.htm

14. Minayo MCS. Pesquisa social: teoria, método e criatividade. 29a ed. Petrópolis: Vozes; 2010.

15. Ministério da Saúde (BR), Conselho Nacional de Saúde. Comissão Nacional de Ética em Pesquisa (CONEP). Resolução n 466/2012: sobre pesquisas envolvendo seres humanos. Brasília; 2012.

16. Marin AH, Falceto OG, Collares M, Lorenzzoni PL, Ferrando JO, Fernandes CLC, et al. A não aceitação da gravidez e o desenvolvimento de crianças com quatro anos de idade no bairro Vila Jardim, Porto Alegre, Rio Grande do Sul, Brasil.Rev Bras Med Fam Comunidade. 2012; 7(25):240-6.

17. Almeida NAM, Medeiros M, Souza MR. Perspectivas de dor do parto normal de primigestas no período pré-natal. Texto \& Contexto Enferm [Internet]. 2012 [acesso em 2017 Jun 27];21(4):819-27. Disponível em: http://www.scielo.br/scielo. php?script=sci_arttext\&pid=S0104-07072012000400012

18. Aissa TF, Oba MV, Pinto MCRLR, Scandiuzzi RJ, Soares DW, Gomes DF. A representação social da primigesta em relação ao parto. Cadernos ESP [Internet]. 2014 [acesso em 2017 Jun 23];8(1):11-19. Disponível em: http://www.esp.ce.gov.br/ cadernosesp/index.php/cadernosesp/article/view/166/86

19. Fleming V, Meyer Y, Frank F, Van Gogh S, Schirinzi L, Michoud B, et al. Giving birth: Expectations of first time mothers in Switzerland at the mid point of pregnancy. Women Birth. 2017;(16):30278-5.

20. Rios CTF, Vieira NFC. Ações educativas no pré-natal: reflexão sobre a consulta de enfermagem como um espaço para educação em saúde. Ciênc Saúde Coletiva [Internet]. 2007 [acesso em 2015 Set 01];12(2):477-86. Disponível em: http:// www.scielo.br/pdf/csc/v12n2/a24v12n2.pdf

21. Cardoso ASF, Dall'Agnol CM. Processo grupal: reflexões de uma equipe de enfermagem. Rev. esc. enferm. USP [Internet]. 2011 [acesso em 2015 Mai 26]; 45(6): 1412-1418. Disponível em: http://www.scielo.br/pdf/reeusp/v45n6/v45n6a19.pdf

22. Bastos ABBI. A técnica de grupos-operativos à luz de Pichon-Rivière e Henri Wallon. Psicól inf. [Internet]. 2010 [acesso em 2015 Set 01]; 14(14): 160-169. Disponível em: http://pepsic.bvsalud.org/pdf/psicoinfo/v14n14/v14n14a10.pdf

23. Loomis ME. Groupsprocess for nurses. Saint Louis: Mosby Company; 1979.

24. Ghasemi S, Nazari M, Vafaei H, Fararouei M. The Impact of Educational Intervention Based on the Theory of Planned Behavior in Choosing Delivery Mode in Primigravida Pregnant Women. International Journal of Women's Health and Reproduction Sciences [Internet]. 2017 [acesso em 2017 Jun 18]; 5(1):47-54. Disponível em: http://www.ijwhr.net/pdf/ pdf_IJWHR_198.pdf

25. Kizilirmak A, Baser M. The effect of education given to primigravida women on fear of childbirth. Appl Nurs Res. 2016;29:19-24.

26. Nejad FSSA, Golmakani N, Pour NA, Shakeri MT. Effect of Progressive Muscle Relaxation on depression, anxiety, and stress of primigravid women. Evidence Based Care J. 2015;5(1):67-76.

27. Pichon-Rivière E. O processo grupal. 12a ed. São Paulo: Martins Fontes; 2000.

28. Nogueira ALG, Bouttelet MD, Magali FC, Ferreira SL. Pistas para potencializar grupos na Atenção Primária à Saúde. Rev Bras Enferm [Internet]. 2016 [acesso em 2017 Jun 21]; 69(5):964-71. Disponível em: http://www.scielo.br/scielo. php?pid=S0034-672016000500964\&script=sci_abstract\&tlng=pt

29. Almeida SP, Soares SM. Aprendizagem em grupo operativo de diabetes: uma abordagem etnográfica. Ciênc Saúde Coletiva [Internet]. 2010 [acesso em 2014 Nov 17];15(Supl 1): 1123-32. Disponível em: http://www.scielo.br/pdf/csc/v15s1/020. pdf

30. Pereira TTSO. Pichon-Rivière, a dialética e os grupos operativos: implicações para pesquisa e intervenção. Rev SPAGESP [Internet]. 2013 [acesso em 2015 Set 09];14(1):21-9. Disponível em: http://pepsic.bvsalud.org/pdf/rspagesp/v14n1/ v14n1a04.pdf 
31. Zampieri MFM, Gregório VRP, Custódio ZAO, Regis M, Brasil C. Processo educativo com gestantes e casais grávidos: possibilidade para transformação e reflexão da realidade. Texto \& Contexto Enferm [Internet]. 2010 [acesso em 2015 Fev 12];19(4):719-27. Disponível em: http://www.scielo.br/pdf/tce/v19n4/15.pdf

32. Ministério da Saúde (BR), Secretaria de Atenção à Saúde, Departamento de Atenção Básica. Atenção ao pré-natal de baixo risco. Brasília: Ministério da Saúde; 2012.

33. Gazzinelli MF, Souza V, Fonseca RMGS, Fernandes MM, Carneiro ACLL, Godinho LK. Práticas educativas grupais na atenção básica: padrões de interação entre profissionais, usuários e conhecimento. Rev Esc Enferm USP [periódico na Internet]. 2015 [acesso em 2017 Jun 20];49(2):284-91. Disponível em: http://www.scielo.br/pdf/reeusp/v49n2/pt_00806234-reeusp-49-02-0284.pdf

34. Silva RMMD, Viera CV. Acceso al cuidado de la salud del niño en servicios de atención primaria. Rev Bras Enferm [Internet]. 2014 [acesso em 2017 Jun 27];67(5):794-802. Disponível em: http://www.scielo.br/scielo.php?script=sci_ arttext\&pid=S0034-71672014000500794\&lng=en

35. Fernandes MTO, Silva LB, Soares SM. Utilização de tecnologias no trabalho com grupos de diabéticos e hipertensos na Saúde da Família. Ciênc Saúde Coletiva [Internet]. 2011 [acesso em 2015 Ago 20];16(Supl 1):1331-40. Disponível em: http://www.scielo.br/pdf/csc/v16s1/a67v16s1.pdf

\section{Endereço para correspondência:}

Maria Adelane Monteiro da Silva.

Universidade Estadual Vale do Acaraú - UVA

Centro de Ciências da Saúde

Av. Comandante Maurocélio Rocha Ponte, 150

Bairro: Campus Derby

CEP: 62041-040 - Sobral - CE - Brasil

E-mail: adelanemonteiro@hotmail.com 